\title{
A primeira infância vai à escola: em defesa do ensino desenvolvente para todas as crianças
}

\author{
Early childhood goes to school: in defense of developmental \\ teaching for all children
}

Lucinéia Maria Lazaretti ${ }^{1}$

Giselle Modé Magalhães ${ }^{2}$

\begin{abstract}
RESUMO
O debate sobre a educação da primeira infância apresenta desafios e posicionamentos controversos sobre o seu caráter formal e escolar. Neste sentido, este texto objetiva explicitar as características do processo de desenvolvimento na primeira infância, a fim de evidenciar as implicações positivas do ensino escolar nesse processo. Fundamentado na Psicologia HistóricoCultural, percorre uma linha argumentativa evidenciando o processo histórico de luta pelo direito à educação; a especificidade do desenvolvimento infantil e as condições necessárias para o bom ensino, desde a mais tenra idade. Defendemos a sistematização da Educação Infantil de forma a garantir o ensino desenvolvente na primeira infância em suas máximas possibilidades.
\end{abstract}

Palavras-chave: Primeira Infância. Educação Escolar. Psicologia Histórico-

\begin{abstract}
The debate on early childhood education presents controversial challenges and positions on its formal and scholarly nature. In this sense, this text aims to explain the characteristics of the development process in early childhood, in order to highlight the positive implications of school teaching in this process. Based on Historical-Cultural Psychology, it goes through an argumentative line, evidencing the historical process of struggle for the right to education; the specificity of child development and the conditions that are necessary for good teaching from an early age. We defend the systematization of Early Childhood Education in order to guarantee the developmental teaching in early childhood in its maximum possibilities.
\end{abstract}

Keywords: Early Childhood. School education. Historical-Cultural Psychology.

\footnotetext{
${ }^{1}$ Professora Adjunta da Universidade Estadual do Paraná (UNESPAR-Pvaí). Doutora em Educação pela UFSCar. E-mail: lucylazaretti@gmail.com

2 Professora Adjunta no Departamento de Educação da Universidade Federal de São Carlos (UFSCar). Doutora em Educação Escolar pela UNESP (Araraquara). E-mail: 


\section{Introdução}

O ensino escolar na primeira infância ainda é objeto de muitas controvérsias entre os pesquisadores da área. Por um lado, há aqueles com posicionamentos favoráveis à educação em instituições de caráter formal desde os primeiros anos, como resultado de um processo histórico, político e econômico (KUHLMANN, 2005; ROSEMBERG, 2014; HADDAD, 1981). Por outro, aqueles com apontamentos que questionam o atendimento coletivo para as crianças menores de três anos, justificados pelos riscos à saúde e prejuízos aos vínculos afetivos, os quais, por sua vez, geram culpa, insegurança e outros sentimentos por parte da mãe (COSTA, 1984; VIEIRA, 1988; WEBER et al., 2006). Longe de encerrar esse debate, através de argumentação com problemáticas teóricas e práticas, tensionamos neste artigo a discussão sobre a referida temática, uma vez que afirmamos a necessidade de posicionamento político frente a atual conjuntura brasileira.

Em recente texto produzido por Tunes e Prestes (2019), as autoras retomam o debate sobre a educação nos primeiros três anos de vida, a função educativa nesse momento, e o papel das instituições no desenvolvimento das crianças. Tunes e Prestes (2019) defendem que "até os três anos, toda criança tem o direito inalienável de ser acolhida e conviver num ambiente de intimidade com os adultos que, com ela, aprenderam a decifrar os seus sinais e sintomas" (TUNES; PRESTES, 2019, p. 39, grifos no original). Afirmam que o ambiente mais adequado para garantir este direito é o doméstico familiar, pois educar essas crianças significa protegê-las do mundo, e defendem, ainda, que as instituições sociais que se destinam a cuidar de crianças até os três anos de idade não podem garantir essa proteção, cuidado e convivência íntima para decifrar os seus sinais. Em uma longa citação, porém necessária, identificamos em quais argumentos se pautam para defender que o ambiente doméstico e a proteção da família são os elementos da educação ideal para bebês e crianças na primeira infância: 
faltaria aos pedagogos e cuidadores encarregados dos cuidados e atenção a essas crianças a possibilidade de interpretar corretamente os sinais que delas advêm, dada a ausência de convivência íntima com elas no período anterior à sua chegada à instituição. Ademais, ainda que essa convivência possa estabelecer-se a partir do momento de sua chegada, não há dúvidas de que ela será muito mais precária do que a que se verifica no ambiente doméstico da maioria das famílias. Em segundo lugar, por mais bem preparados que estejam pedagogos e cuidadores e muito se saiba acerca das peculiaridades do desenvolvimento da criança nessa idade, cada criança é uma singularidade irreplicável. Logo, o que se pode saber dela, necessariamente, advém dela mesma, mas interpretativamente, uma vez que ainda não sabe falar e sequer tem consciência de seu "eu". Em terceiro lugar, os sinais e sintomas das crises que acontecem nesse período etário são diferentes para cada criança e seu aparecimento não é definido pelo relógio. Eles podem começar a ocorrer aos 24 meses para uma criança, aos 30 para outra, por exemplo; podem durar dois meses para uma; cinco meses ou um ano para outra; podem manifestar-se de maneira radicalmente distinta de uma criança para outra. Considerando-se a peculiaridade da consciência da criança nessa idade, será necessária uma forma específica de atuação e de organização do ambiente social de desenvolvimento para cada modo de manifestação das crises. Essa flexibilidade máxima e constante não é possível nas instituições, pois elas requerem alguma padronização perdurável para que possam funcionar. Sem dúvida, o ambiente doméstico guarda maiores possibilidades para essa flexibilização, uma vez que os pais têm mais condições de descobrirem as diferentes possibilidades de sua criança, mesmo nos casos em que se manifestam sintomas de desenvolvimento atípico (TUNES; PRESTES, 2019, p. 39).

A citação evidencia argumentos que nos instigam a pensar sobre a função dos profissionais das instituições educativas frente às especificidades deste momento do desenvolvimento humano, colocando aos leitores uma importante questão social: o que fazer com nossas crianças pequenas? as crianças na primeira infância ${ }^{3}$ devem ir para a escola? Teria a escola o que ensinar para esta faixa etária?

Faz-se importante ressaltar que a base teórico-metodológica de análise das autoras para pautarem seus argumentos é a Psicologia Histórico-Cultural. Partindo da mesma perspectiva teórica, e, também, já sinalizando nossa resposta

\footnotetext{
${ }^{3}$ Não utilizamos marcos cronológicos para delimitar os períodos, mas Elkonin (1987) aponta a primeira infância entre, aproximadamente, o segundo e o terceiro ano de vida. 
às questões anteriores, o objetivo do presente texto é explicitar as características do processo de desenvolvimento na primeira infância a fim de evidenciar as implicações positivas do ensino escolar nesse processo.

Assim sendo, percorreremos uma linha argumentativa organizada em três momentos: a) Como conquistamos o direito da criança à educação e à luta histórica pela educação infantil? b) Como se dá a formação da consciência da criança nos primeiros anos de vida? c) Quais as condições necessárias para o bom ensino na educação da primeira infância?

De antemão, antecipamos que o presente artigo vem ao encontro do necessário e respeitoso diálogo científico. Os argumentos aqui apresentados foram construídos a partir de posicionamentos incorporados não só em nossa formação acadêmica, mas também a partir de nossa atuação na educação básica, no ensino superior, de nossas pesquisas, e, principalmente, de nossa militância e atuação política em defesa do direito à educação que promova desenvolvimento desde os primeiros anos de vida.

\section{De quê educação infantil se trata? Recuo ao mal necessário ou função educativa?}

Em tempos de retrocesso político, circulam ideários de senso comum que vão firmando-se em forma de políticas públicas e, muitas vezes, a disputa de interesses antagônicos fica latente. Atualmente, assistimos, a passos largos, o retorno de políticas assistenciais e alternativas, tais como: programa criança feliz; creche domiciliar; vale creche; cuidador infantil; entre outros que vão na contramão de toda a discussão sobre o direito da criança à educação e os avanços científicos pedagógicos que envolvem o processo de aprendizagem infantil. Neste contexto, recuperar alguns marcos históricos, políticos e pedagógicos se faz necessário para compreender a gravidade de argumentos que sinalizam o recuo a tendências informais e familiaristas, que esmagam direitos sociais e opõem-se aos debates e políticas públicas sobre educação e primeira infância. Precisamos reiterar o óbvio e (re)colocar no centro do debate o direito à educação como conquista histórica, resistindo aos retrocessos. 
Historicamente, no Brasil, para a primeira infância, a creche foi uma alternativa para as mães trabalhadoras, um recurso reivindicado pela legislação trabalhista, que cumpria a função de assistência social. Ou seja, desde o final do século XIX, a creche pública atende crianças pobres, filhos e filhas de mães trabalhadoras. Logo, não se origina como uma política pública educacional, demarcando o lugar social dessas crianças e, também, a instituição destinada a elas como um mal necessário. Era mal, porque produzia o afastamento das mães, carências afetivas, distúrbios digestivos, entre outros argumentos, baseados nas normas médico-higiênicas, os quais questionavam a função da creche, advogando que esta não garantia a preservação da saúde e integridade física dos bebês e crianças pequenas. E era necessário, dada a configuração social dos centros urbanos, desorganizados e palco de desajustes morais e econômicos, os quais obrigavam as mulheres a renunciar a seu lar para garantir a sobrevivência da família (COSTA, 1884; VIEIRA, 1988).

Como ressalta Rosemberg (1984), as creches ganharam um caráter de instituição provisória:

O fato da reivindicação/concessão de creches ter se justificado principalmente pela necessidade/vontade de a mãe trabalhar fora de casa, acabou por emprestar à creche o caráter de instituição provisória, de emergência ou de substituição, acarretando-lhe uma história cíclica, restringindo-a a apenas a uma parte das famílias, dificultando o acúmulo de experiências, tanto a nível de seu funcionamento interno quanto da população usuária (ROSEMBERG, 1984, p. 74).

Essa condição histórica da creche, como cíclica, com poucos avanços e muitos recuos, é o que assistimos na atualidade. Na Constituição Federal Brasileira de 1988, o artigo 208 assegura à criança o Direito à Educação, como dever do Estado e opção da Família e, quando trata da Educação Infantil, assevera: "O dever do Estado com a educação será efetivado mediante a garantia de: (...) IV atendimento em creche e pré-escola às crianças de zero a seis anos de idade" (BRASIL, 1988, p. 35). Esse direito constitucional é firmado com a promulgação da Lei de Diretrizes e Bases da Educação Nacional (LDBEN, 9394/96) que estabelece 
a educação infantil como a primeira etapa da Educação Básica Nacional e define que, em seu art. 30, inciso I e II: creche para designar o atendimento de crianças de zero a três anos e, pré-escola, para crianças de 4 a 6 anos $^{4}$.

Nesse contexto, Rosemberg (2014) afirma que, embora já tenhamos algumas conquistas, ainda há muito que avançar quando refletimos sobre as políticas públicas para a Educação Infantil brasileira. Com esse ordenamento legal e político, e visando superar o atendimento pobre para pobre, a preocupação volta-se para garantir condições mínimas necessárias para propostas e estratégias que visem qualidade, resultando em uma série de documentos oficiais que, desde 1993, o Ministério da Educação (MEC) procurou implementar como uma política pública de Educação Infantil democrática e com qualidade (ROSEMBERG, 2014). De lá para cá, a implementação de diretrizes e normatizações ampliaram concepções de Educação Infantil, criança e infância, conquistando avanços importantes nas práticas pedagógicas. São conquistas importantes, mas ainda insuficientes frente ao cenário político, econômico e social, marcado pela desigualdade e descompasso nas garantias legais.

Um descompasso é o acesso desigual à Educação Infantil, ainda mais com a versão de 2013 da LDBEN, Lei nº 9394/96, que institui, com a Emenda Constitucional 59/09, a obrigatoriedade da matrícula na educação básica de crianças a partir de 4 anos de idade, acirrando uma cisão na Educação Infantil: prioriza-se as crianças maiores, aproximando-as do Ensino Fundamental, principalmente, em termos de proposta pedagógicas e critérios de avaliação, e os bebês e crianças pequenas ficam refém de soluções dúbias para resolver a dívida histórica de acesso à vaga. Para ilustrar em termos estatísticos, no Brasil, aproximadamente $32 \%$ da população menor de três anos está na Educação Infantil (BRASIL, 2018). Ocorre que, regionalmente, existem estados e municípios que não cobrem nem 10\% desse público, principalmente nos estados com menor renda e mais vulneráveis economicamente. Esses dados assinalam o desafio de dar visibilidade à creche e de

\footnotetext{
${ }^{4}$ Em 2013, esse inciso foi revogado pela Lei $n^{0} \underline{12.796}$ e as pré-escolas destinam-se às crianças de 4 (quatro) a 5 (cinco) anos de idade. 
integrá-la plenamente ao sistema educacional e a necessidade de combater os modelos familiaristas, que assombram o cenário atual.

Para que o passado e o presente não se convertam na maldição de Sísifo, de um eterno retorno ao ponto de partida, é necessário, que pelo menos, se fique alerta quanto à introdução de "novidades" que desestabilizam modelos formais e completos de Educação Infantil, particularmente de creche, para reduzir o déficit de vagas referente à população não atendida. Trata-se do risco que tenho enunciado como "assistencialização" da creche, ou seja, do ressurgimento sistemático de soluções milagrosas que dariam conta do déficit de vagas em creche particularmente para a população situada nos níveis inferiores de renda (ROSEMBERG, 2014, p. 177).

Com esse cenário, precisamos assumir: no Brasil, em decorrência da conjuntura econômica e social da maior parte da população, com desenfreado crescimento de desigualdades e pobreza, é preciso políticas efetivas para que as crianças menores de três anos tenham seu direito garantido de acessar e frequentar instituições de Educação Infantil. Garantida a permanência e ampliação das políticas públicas que se firmaram nas últimas três décadas, podemos dialogar sobre que Educação Infantil se trata, em termos de qualidade. Para isso, é fundamental compreender quem são os bebês e crianças pequenas que estão na educação infantil e quais as principais características desse processo de aprendizagem e desenvolvimento.

\section{Características da formação da consciência na primeira infância: em defesa do} caráter intencional das instituições de educação infantil.

Para dialogar com a qualidade da Educação Infantil disponibilizada para nossas crianças e defender o ensino promotor de desenvolvimento, faz-se fundamental conhecermos o processo de formação da consciência na primeira infância, assim como as especificidades deste psiquismo. É certo que a consciência humana se configura de forma diferente ao longo do nosso desenvolvimento, sendo diretamente condicionada pela atividade que desempenhamos em cada momento da vida. Conforme Leontiev (2001), as 
circunstâncias concretas da vida da criança alteram o lugar que ela objetivamente ocupa no sistema das relações humanas, o que gera novas demandas para a organização do psiquismo e, consequentemente, da consciência. "Ao estudar o desenvolvimento da psique infantil, nós devemos, por isso, começar analisando o desenvolvimento da atividade da criança, como ela é construída nas condições concretas de vida" (LEONTIEV, 2001, p. 63).

Assim, o primeiro ano de vida é marcado pela máxima dependência do adulto e pelas mínimas possibilidades de comunicação, o que Vigotski (1996) denomina como a primeira grande contradição humana. Imersos nessa contradição, bebê e adulto estabelecem entre si o que Elkonin (1987) denomina de comunicação emocional direta, atividade-guia 5 no primeiro ano de vida, por meio da qual as necessidades do bebê são atendidas. Sem a interposição de palavras, o adulto estabelece uma comunicação com o bebê que o permite interpretar e atender suas necessidades, sejam elas de alimentação, dor, sono, frio etc.

Como polo oposto e contrário interno à comunicação emocional direta com o adulto, temos um psiquismo pouco diferenciado, que começa a se especializar conforme a internalização dos signos da cultura. Vigotski (1996; 2018) aponta a percepção como a função psicológica que ganha destaque no primeiro ano de vida, pois todas as outras realizam-se por meio dela. É a atividade de comunicação emocional direta que vai demandando a especialização da percepção e do aparato motor, desenvolvendo gradativamente um sistema percepto-afetivo-motor. Como produto desta organização interfuncional dependente da percepção, teremos uma organização da consciência que ainda não distingue o eu do nós, o que Vigotski (1996) denomina de protoconsciência do nós, ou seja, uma consciência que funciona interpsiquicamente.

Desta forma, ao final do primeiro ano de vida, o bebê se comunica afetivamente com o adulto e, ao ser afetado pelos objetos e pessoas ao seu redor, opera em sua realidade objetiva à medida que manipula objetos, sorri, chora, observa o seu entorno, emite sons. A exploração de objetos, denominada de

\footnotetext{
${ }^{5} \mathrm{O}$ conceito de atividade-guia pode ser encontrado nos trabalhos de Leontiev (2001). Trata-se da atividade que incide diretamente na formação da personalidade em cada período do desenvolvimento e por meio da qual outras ações podem ser desenvolvidas. A atividade-guia não surgirá naturalmente, mas sim como demanda social. 
movimentos reiterativos e concatenados (ELKONIN, 1998), ganha destaque no primeiro ano de vida e cria a demanda para a atividade objetal-manipulatória, que guiará o desenvolvimento na primeira infância.

Isso significa que a exploração sensório-motora é conquista do primeiro ano de vida e permite gradualmente aos bebês alguns movimentos com os objetos, os quais proporcionarão o salto qualitativo para a ação propriamente objetal, organizada pela linguagem. É o domínio dos procedimentos socialmente elaborados de ação com os objetos a característica principal da primeira infância, denominada por Elkonin (1987) de atividade objetal-manipulatória. A conduta da criança, neste momento da vida, é extremamente dependente da situação, o que caracteriza a organização da sua consciência. Isso quer dizer que os objetos têm um caráter imperativo: atraem e repelem diretamente a criança; eles induzem-na a agir. Uma porta incita a ação de fechá-la; escadas a convidam a subir ou descer e há muitos outros exemplos que poderíamos extrair do nosso cotidiano de vida com crianças pequenas.

Se no primeiro ano de vida a comunicação com o adulto era direta, na primeira infância esta passa a ser mediada pelos objetos e organizada pela linguagem, pois a criança está imersa em uma cultura de falantes. É o adulto que não só disponibiliza os objetos para a criança, como também fala para as crianças sobre esse mundo de coisas das quais ela está se apropriando. Assim, a atividade objetal-manipulatória demandará uma nova formação psíquica na criança, qual seja: o entrecruzamento da linguagem com o pensamento. A unidade percepção-afecção-ação, que se formou no primeiro ano de vida, tende a ser quebrada pelo intenso desenvolvimento da linguagem nesse período (MAGALHÃES, 2018), pois as palavras têm papel fundamental como interposição antes da ação. Dito de outra forma, as palavras passam a orientar as ações das crianças com os objetos e adquirem, como afirmou Vigotski (2001), a função de signo dos $\operatorname{signos}^{6}$, ou seja, conforme Magalhães (2018), representam uma imagem já significada na consciência da criança.

O desenvolvimento da linguagem certamente é um marco fundamental do desenvolvimento cultural, pois condensa um acúmulo de experiências humano-

\footnotetext{
${ }^{6}$ Os signos, para Vygotski (1995), são imagens que ganham significado e agem como instrumento psicológico, modificando o psiquismo. 
genéricas. A linguagem, para Vigotski (2001), não só opera como meio de comunicação, mas também como instrumento da atividade intelectual, tendo como sua unidade mínima a palavra, parte essencial da fala, que por sua vez é o "meio especial de comunicação vocal e oral que usa a linguagem para, fundamentalmente, transmitir informações" (MARTINS, 2013, p. 167).

No princípio do desenvolvimento da fala, segundo Martins (2013), há uma relação primária entre palavra (som), percepção e representação (imagem), o que ainda não corresponde à linguagem propriamente dita, mas sim à fase prélinguística. Ou seja, trata-se de uma conexão externa entre palavra e objeto e não uma conexão interna entre signo e significado. A conversão da imagem do objeto em signo exige a formação embrionária dos equivalentes funcionais dos conceitos, que são os primórdios do entrecruzamento da linguagem com o pensamento, e possibilita uma "forma totalmente nova de comportamento, exclusivamente humana" (VIGOTSKI, 2001, p. 172).

O entrecruzamento da linguagem com o pensamento é revolucionário no desenvolvimento infantil, pois esta é uma neoformação que requalifica toda a interfuncionalidade psíquica e, consequentemente, a consciência da criança pequena, denominada nesse momento de consciência do eu-externo (VIGOTSKI, 1996), uma vez que a atividade objetal-manipulatória imersa na linguagem demanda a separação do mundo externo e do mundo interno, e a criança passa a reconhecer-se como parte desse mundo. O significado da palavra leva à generalização, que é tarefa do pensamento. Por isso, Martins (2013, p. 172) afirma que "a palavra passa a ocupar um outro lugar na vida da pessoa, imposto tanto pela necessidade de comunicação em si, quanto pela necessidade de compreensão sobre o mundo".

Desta forma, ao compreender o desenvolvimento global da criança na primeira infância, evidencia-se um processo que parte das funções sensoriais, perceptivas e motoras, e, sob condições adequadas de educação, permite o desenvolvimento da linguagem, da fala e da compreensão do significado que as palavras carregam. O processo de desenvolvimento global da criança na primeira infância nos aponta como eixo central o desenvolvimento da linguagem, que ultrapassa o pareamento externo de determinado objeto com uma palavra (som), mas que demanda do pensamento da criança a compreensão dos significados socialmente instituídos nas ações com os 
objetos. Isso significa que é preciso falar com a criança e ensinar a criança a falar, mas não repetindo sons associados a objetos, e, sim, disponibilizando para ela objetos que a permitam compreender o mundo e a história contida neles.

Diante de tais características e especificidades, acreditamos já ser possível afirmar que não se trata de um momento da vida que exija somente proteção e acolhida, pois existem processos interfuncionais em desenvolvimento sendo demandados por atividades específicas em cada momento da vida da criança. $\mathrm{O}$ ambiente familiar pode atender às demandas da atividade do bebê e da criança pequena, mas não o fará de forma sistematizada e cientificamente orientada como devem fazer as instituições de educação infantil. Os profissionais da educação infantil têm melhores condições de identificarem o desenvolvimento real das crianças pequenas e promoverem novas formações psíquicas e novas formações da consciência por meio do ensino.

A educação da criança é objeto da família e da escola. São duas instituições responsáveis por esse processo, porém, com finalidades distintas. Não podemos sobrepor e nem desvalorizar a formação familiar, a constituição de vínculos e a responsabilidade de atender às necessidades infantis, com afeto, segurança, proteção, cuidado e aproximação do bebê com a realidade circundante. No entanto, a educação escolar não se limita a proteger e atender as necessidades mais emergentes do bebê e da criança, mas sim apresentar o mundo da cultura, de forma sistemática e organizada. A função social da educação infantil é, por meio de um ensino organizado e sistemático, ampliar os horizontes culturais do bebê e da criança pequena. Isso significa que os signos e instrumentos culturais devem ser apresentados à criança e são mediadores da aprendizagem e do desenvolvimento infantil.

É certo que os momentos de transição de uma atividade para outra, e, consequentemente, de reorganização da consciência da criança, exigem maior atenção educativa, pois são períodos críticos que, quando não bem compreendidos, podem abrir espaços para o que Vigotski (1996) denominou de crises do desenvolvimento. Isso significa que, em absoluto, as crises sejam processos naturais que necessariamente irão acontecer ao longo do desenvolvimento. As crises nos mostram períodos de transição que requerem a nossa atenção educativa, pois nos indicam que novas necessidades estão surgindo a partir da atividade já estabelecida Obutchénie: R. de Didat. e Psic. Pedag.|Uberlândia, MG|v.3|n.3|p.1-21|set./dez. 2019 ISSN: 2526-7647 
e que é preciso que o adulto mude a sua forma de tratar a criança. Estariam as famílias aptas a identificarem os períodos de transição como estão os(as) professores(as) de educação infantil7? Ou poderiam estas intensificar a manifestação das crises ao invés de convertê-las em um novo período do desenvolvimento?

Sob o nosso ponto de vista, a defesa da família como único ambiente adequado para o desenvolvimento da criança pequena desconsidera a determinação social da própria família, tratando-a de forma idealizada. Faz-se importante reafirmar que as famílias têm diferentes configurações históricas (REIS, 2012) e que também estão submetidas às políticas públicas precárias e provisórias. Isolar a criança de ambientes e instituições que a façam conviver com o coletivo pode, inclusive, reforçar o individualismo já tão presente nas relações sociais capitalistas, além de culpabilizar as mães trabalhadoras por não terem outra opção para seus filhos(as) (ROSEMBERG, 1974; WEBER et al., 2006). Se nos individualizamos e nos formamos pelo tecido social, então, também é a sociedade em sua totalidade a responsável por nosso desenvolvimento, nisso estão inclusos tanto a família como a escola de educação infantil.

Resta-nos, então, responder: como a escola de educação infantil pode dar conta desta tarefa? Ou, em outras palavras, o que é o bom ensino de crianças pequenas dentro das instituições de educação infantil?

\section{Condições necessárias para se efetivar um bom ensino na primeira infância.}

Muitas vezes aprisionadas em uma rotina inflexível e esgotante, restrita a atender necessidades básicas de sono, alimentação, segurança e higiene, com o uso do espaço da sala de aula ocupado por berços e bebês-conforto, paredes repletas de adornos estereotipados com letras e números, dentre outros adereços em espuma sintética (e.v.a), as práticas pedagógicas da primeira infância, conforme Lazaretti (2013), apresentam alguns equívocos no modo de organizar o ensino. Entendemos que essa organização, se somada a uma precariedade no

\footnotetext{
7 Não discutiremos nesse artigo a formação dos(as) professores(as) no Brasil. No entanto, é este o (a) profissional capaz de compreender o desenvolvimento e promovê-lo dentro das instituições educativas. Obutchénie: R. de Didat. e Psic. Pedag.|Uberlândia, MG|v.3|n.3|p.1-21| set./dez. 2019 ISSN: 2526-7647 
ambiente e prejuízos na formação do(a) professor(a), pode inviabilizar práticas que atendam às particularidades dos bebês e crianças pequenas, como preocupam-se Tunes e Prestes (2019).

No entanto, consideramos que algumas práticas pedagógicas ainda se assentam nessa configuração por falta de clareza quanto à função da educação infantil e pela ausência de uma concepção de criança e desenvolvimento, ou seja, ainda é preciso diferenciar modelos formais e informais na Educação Infantil. (MARTINS; MAGALHÃES, 2014) Interessa-nos, como critério de tal diferenciação, os objetivos que orientam as práticas, os conteúdos que veiculam, os encaminhamentos didáticos utilizados para atingir os objetivos e, principalmente, o papel do professor na promoção do desenvolvimento (MARTINS; MAGALHÃES, 2014). É nesta direção que argumentaremos, neste momento, a fim de apresentar algumas condições favoráveis ao bom ensino.

Primeiramente, é preciso a clareza de que cabem às instituições educativas formais garantir a formação da "segunda natureza" da criança, ou seja, aquilo que não é garantido pela natureza e precisa ser produzido historicamente (SAVIANI, 1991), por isso é insuficiente que se limitem a proteger e cuidar dos bebês e crianças pequenas. Nos aportes da Psicologia Histórico-Cultural, produzir essa segunda natureza implica em formar características humanas não naturais, tais como as funções psicológicas superiores, que surgem como novas formações vinculadas ao emprego de signos e ao uso de instrumentos (VYGOTSKI; LURIA, 2007). Assim, é o acúmulo de experiências históricas da humanidade que deve ser disponibilizado para as crianças pelas instituições educativas (SAVIANI, 1991), de modo a formar seres humanos capazes de transformar a realidade objetiva e, em última instância, superar as relações sociais de dominação.

Nesta direção, é evidente que "o domínio desta experiência social é um processo extraordinariamente complexo e não pode ser obtido por uma aproximação passiva de mera contemplação da realidade circunvizinha" (ELKONIN; APOROZHETS, 1974, p. 20, tradução nossa). As práticas pedagógicas na educação da primeira infância devem ser organizadas e orientadas para ampliar as formas de domínio dos signos e instrumentos objetivados na experiência social. Isso implica refletir sobre as condições e 
circunstâncias mais favoráveis às aprendizagens infantis, já que "o único bom ensino é o que se adianta ao desenvolvimento" (VIGOTSKI, 1988, p. 114).

É indubitável sustentar e mirar uma prática pedagógica fundamentada e coerente para desenvolver ações favoráveis ao desenvolvimento infantil, o qual começa a formar-se por meio do processo de ensino efetivado pelos adultos. Os adultos, além de satisfazerem as necessidades imediatas do bebê, organizam a sua vida, promovendo as condições necessárias para que seja formada a experiência social, por meio da atividade conjunta e compartilhada (ELKONIN, 1969, grifo nosso). Isso significa que, na instituição escolar, o(a) professor(a), ao atender às necessidades primordiais das crianças, vai progressivamente as aproximando da experiência social, expressa na apropriação da linguagem, na atuação com os objetos, na exploração espacial, entre outras conquistas do desenvolvimento.

A prática pedagógica orientada para aproximar e garantir que as crianças se apropriem da experiência social, significa que extrai dessa cultura os conteúdos de ensino que serão os mediadores para atingir os objetivos propostos. Esses conteúdos, objetivados historicamente, precisam ser selecionados, sistematizados e organizados por áreas, tais como arte, ciências da natureza e da sociedade, matemática, cultura corporal, língua portuguesa. Essas áreas, como sínteses da sistematização do conhecimento humano acumulado, podem compor um currículo, entendido como instrumento orientador do trabalho educativo para efetivar e assegurar que as ações de ensino permitam às crianças atuarem no mundo objetivo, sentirem e perceberem sons, cores, texturas, sabores, cheiros, compreenderem o vocabulário adulto e emitirem suas primeiras palavras, dentre outras formas de manifestação da linguagem, generalizadas nos conteúdos escolares.

Nesse entendimento, na escola de educação infantil, os conteúdos escolares cumprem uma dupla função quando apropriados pelas crianças em uma relação ativa e mediada: aproximam e ampliam a compreensão de mundo, dos fenômenos e objetos humanos, e, simultaneamente, formam funções psíquicas, tais como sensações, percepção, linguagem, pensamento, entre outras (LAZARETTI; ARRAIS, 2018). Para que esses conteúdos sejam convertidos em propriedades individuais das crianças e internalizem-se como instrumentos simbólicos, é preciso operacionalizar 
formas adequadas de ensino, ou seja, trata-se de organizar os meios: recursos; instrumentos; espaço; tempo; procedimentos (SAVIANI, 1991).

Nas instituições educativas da primeira infância, é comum nos depararmos com práticas empobrecidas, nas quais os objetos disponibilizados aos bebês e crianças pequenas servem para simples manuseio, muitas vezes selecionados aleatoriamente, cuja finalidade é distração e passatempo. Partindo do pressuposto que esses objetos portam significações sociais, têm propriedades (cor, forma, tamanho), e que, progressivamente, a criança, ao apropriar-se das significações verbais expressas nas palavras, apropria-se também de um sistema conceitual que as subjazem, há que se saber como ensinar por meio desses instrumentos. Logo, as ações de ensino devem envolver: selecionar, dispor, organizar objetos que possam ser manipulados pelas crianças, ensiná-la a atuar com eles e, também, apropriar-se de seus atributos conceituais. Estas são condições indispensáveis para o bom ensino na educação infantil, uma vez que possibilitam a complexificação das funções psíquicas e, consequentemente, reorganizam a consciência da criança promovendo desenvolvimento.

Nessa esteira, para organizar o trabalho pedagógico que amplie as experiências sociais dos bebês e crianças pequenas, tornando-as experiências individuais, é preciso considerar qual o melhor tempo e espaço para que essas ações de ensino ocorram. Defendemos que a rotina não pode ser inflexível e padronizada. O tempo, na educação infantil, não pode ser rígido e com fixidez nos horários, e, sim, deve ser entendido como uma construção social, como um elemento que permita ao bebê e à criança pequena aprenderem a regular suas ações no dia-a-dia da instituição e sentirem-se participantes desse lugar, e é importante que eles se localizem e se orientem no tempo a partir de tarefas e situações adequadas.

Não negamos a necessidade de organizar a rotina com estabelecimento de uma sequência de ações básicas, porém o que é inegociável nessa rotina e o que é negociável? Defendemos que, processualmente, o tempo precisa ser compreendido pela criança e deve orientá-la no espaço que pertence. Por isso, o espaço é outro elemento importante para organizar o ensino. No entanto, não podemos considerar o espaço apenas em seu estado físico, mas principalmente refletir com clareza e direção: "Espaço para quê? Espaço para quem e com quem? Espaço com o quê e Obutchénie: R. de Didat. e Psic. Pedag.|Uberlândia, MG|v.3|n.3|p.1-21| set./dez. 2019 ISSN: 2526-7647 
como?" (LAZARETTI; MAGALHÃES, 2018, p. 150, grifos originais). Com essas questões, o professor pode selecionar e organizar ações favoráveis à aprendizagem, compreendendo o espaço como um elemento da organização do ensino, como e o quê está aprendendo, considerando que o espaço proporciona: acolher e ampliar os vínculos afetivos; locomoção e ampla circulação para situações de explorar, experienciar, brincar e conhecer; diversidade de materiais, recursos, instrumentos como mediadores nas ações de ensino; situações novas, que instiguem a curiosidade e interesse dos bebês e crianças, produzindo a possibilidade de construção de motivos; expor e socializar as produções infantis que representem o percurso das aprendizagens e tenham significado e sentido para elas.

Isso significa que o professor não apenas organiza o ambiente e disponibiliza objetos para serem manipulados livremente, mas também medeia a relação criança-objeto, incitando-a a apalpar, apreender, manipular brinquedos e diferentes objetos do uso cotidiano, que são aprendizagens primárias dos produtos e instrumentos da cultura humana. Quanto mais rica e diversificada for essa aprendizagem com os elementos da cultura, mediada pelo professor, maior será a promoção de aprendizagem e desenvolvimento da criança (LAZARETTI; MELLO, 2018, p. 74).

Dito isso, para que seja garantida a articulação entre os elementos (objetivos-conteúdos-encaminhamentos) didáticos, é preciso clareza teórica do(a) professor(a) para planejar e dirigir as ações de ensino (LAZARETTI, 2013). É insuficiente o preparo técnico, muitas vezes, reduzido ao(a) cuidador(a) e/ou agente de apoio, que desconsideram a trajetória histórica no Brasil pela valorização profissional da educação infantil, a qual, por sua vez, estabelece plano de carreira docente com qualificação pedagógica específica, por meio da formação inicial e continuada, piso salarial, entre outras determinações legais (BRASIL, 1996).

Dada a complexidade de organizar o ensino, uma das tarefas do professor de educação infantil é provocar, direcionar, indagar as ações das crianças frente às propriedades dos objetos, ativando as operações do pensamento, tais como comparação, generalização, análise, síntese e, progressivamente, a criação de abstrações, ou imagens subjetivas que atuam como instrumento psíquico. Lazaretti e Mello (2018) explicitam que os objetos trazem significações culturais que tem função e 
forma determinadas para o uso e exploração, e, mediante observação e imitação, em ação conjunta e compartilhada com o(a) professor(a), a criança, progressivamente, aprende a riqueza e a complexidade de funções e significados que eles carregam.

Observando as ações dos adultos com os objetos, o pequeno se apropria das formas humanas da atividade prática objetivada. $\mathrm{Na}$ ação com os objetos, a criança descobre que muitos deles podem ser utilizados de modo similar. Este tipo de descoberta conduz à generalização não somente dos objetos similares (por alguma característica), como também a generalizar a experiência da atividade (MÚJINA, 1979, p. 54, tradução nossa).

Um dos principais signos mediadores dessa relação criança-professor(a) é a linguagem oral. A riqueza na produção verbal, por meio de palavras e sons, amplia e provoca qualitativamente apropriações que propiciam ao bebê e à criança explorar e produzir conhecimentos sobre si e sobre o mundo, possibilitando formas culturais de desenvolvimento (MARTINS, 2007).

A condição do professor que ensina o bebê [e a criança], prioriza formas de comunicação intensa; proporciona conteúdos que ampliam as possibilidades de aprendizagens quanto: ao desenvolvimento da mobilidade espacial, aperfeiçoando seus movimentos e coordenações motoras; enriquecendo os sistemas sensoriais preênsis e de manipulação; incentivando diferentes linguagens; promovendo funções psíquicas como sensação, percepção, emoção, entre outros processos de aprendizagem e de desenvolvimento (LAZARETTI; MELLO, 2018, p. 77).

Desta forma, elencamos algumas condições para organizar a prática pedagógica e demarcar que é possível garantir um bom ensino desde os primeiros anos de vida, dada a clareza da função social da educação infantil e seus impactos na formação e aprendizagens dos bebês e crianças pequenas, sujeitos em pleno processo de humanização. Evidencia-se que uma das principais condições para efetivarmos o bom ensino se deve ao trabalho do(a) professor(a), que exige formação consistente, munido(a) de referenciais teórico-práticos, que permitam compreender a complexidade do desenvolvimento infantil e dos processos de 
ensino, de modo a direcionar suas ações para favorecer e intervir nas conquistas e aprendizagens dos bebês e crianças.

\section{Considerações Finais}

A contradição histórica entre processos de alienação e processos de humanização (BORGES, 2017) ainda se faz presente, afinal, não superamos, até o presente momento, a dominação de uma classe pela outra. Neste sentido, também encontramos na história da educação infantil avanços e retrocessos, ou medidas que caminham para a humanização e medidas que são expressões da alienação social.

Avançamos no aparato legal e estabelecimento de diretrizes específicas para a educação infantil, que tem garantido que a educação escolar formal assegure o acesso desde a mais tenra idade, como também orientações que expressam os avanços teórico-práticos de um ensino desenvolvente. No entanto, os retrocessos se intensificam, principalmente para a primeira infância, com a retomada de propostas informais, emergenciais, de baixo custo, como anunciado na introdução deste artigo, colocando em risco todos as conquistas até aqui garantidas.

Explicitamos, com os argumentos fundamentados na Psicologia HistóricoCultural, o quão preocupante é retomar modelos familiaristas, que desconsideram a especificidade do processo de desenvolvimento dos bebês e crianças pequenas e as implicações positivas do ensino escolar para aprendizagem desses sujeitos, afirmando a importância deste ensino para a humanização de todos e todas. Essa é a função social da educação infantil numa direção humano-genérica, orientada por objetivos em correspondência com os conteúdos escolares objetivados na experiência social, expressa em objetos e fenômenos humanos, para todos e todas, da formação de um ser pelo outro, que são operacionalizados por encaminhamentos didáticos diversos, enriquecidos, contextualizados, resultando assim na formação das complexas e elaboradas conquistas humanas no desenvolvimento cultural das crianças.

Afirmamos, junto com Martins e Magalhães (2014), a urgência da Educação Infantil superar a informalidade institucionalizada e organizar a vida das crianças para além do cotidiano, promovendo o desenvolvimento na primeira infância em suas máximas possibilidades. 
É nesta direção que, não só fazemos a defesa do ensino para as crianças desde o nascimento, como também afirmamos a necessidade da sólida formação dos professores, mediadores do desenvolvimento infantil, e que reiteramos que os domínios teóricos acerca do processo de desenvolvimento histórico-cultural dos indivíduos se colocam como exigência no trabalho educativo formal.

\section{Referências}

BORGES, L.F.P. Educação, escola e humanização em Marx, Engels e Lukács. Revista Educação em questão. Natal, v. 55, n. 45, p. 101 - 126, jul-set, 2017. https://doi.org/10.21680/1981-1802.2017v55n45id12747

BRASIL. Ministério da Educação e Cultura. Lei $n^{\circ}$. 9.394, de 20 de dezembro de 1996. Fixa as Diretrizes e Bases da Educação Nacional. Brasília, DF: MEC, 1996. https://doi.org/10.11606/d.7.2013.tde-10092013-151829

BRASIL. Relatório do $2^{\circ}$ Ciclo de Monitoramento das Metas do Plano Nacional de Educação. Brasília, DF: Inep, 2018. 460 p. Disponível: http://inep.gov.br/informacao-da-publicacao//asset_publisher/6JYIsGMAMkW1/document/id/1476034. Acesso em 26 de maio de 2019. https://doi.org/10.1590/s1413-99362010000300018

COSTA, M. C. L. Creche: solução ou problema? Cadernos de Pesquisa. São Paulo. V. 50, p. 58-60, ago. 1984.

ELKONIN, D. Sobre el problema de la periodizacion del desarrollo psíquico em la infância. In: SHUARE, M. (org.) La Psicologia evolutiva y pedagogica en la URSS. Moscú: Editorial Progreso, 1987, p. 104-124. https://doi.org/10.5093/rhp2019a14

ELKONIN, D. B.; ZAPOROZHETS. Foreword. In: ELKONIN, D. B.; ZAPOROZHETS, A. (Orgs). The psychology of preschool children. Cambridge, MA: MIT Press, 1974. p. 5-23.

ELKONIN, D. Psicologia do jogo. São Paulo: Martins Fontes, 1998.

ELKONIN, Daniil Borisovich. Desarrollo psíquico del niño desde el nacimiento hasta el ingreso en la escuela. In. SMIRNOV, A. A. et al. Psicología. México: Grijalbo, 1969. p.504-522.

HADDAD, L. A creche em busca de identidade. São Paulo: Loyola, 1991. 
LAZARETTI, Lucinéia Maria. A organização didática do ensino na educação infantil: implicações da teoria histórico-cultural. 2013. 204 f. Tese (Doutorado em Educação) - Universidade Federal de São Carlos, São Carlos, 2013. https://doi.org/10.29289/259453942018v28s1022

LAZARETTI, L. M.; ARRAIS, L. F. O Que Cabe no Currículo da Educação Infantil? Um Convite à reflexão Educ. Anál., Londrina, V.3, N.2, p.27-46, jul./dez. 2018. https://doi.org/10.5433/1984-7939.2018v3n2p27

LAZARETTI, L. M.; MAGALHAES, C. . Acolher, Explorar, Brincar e Conhecer: Reflexões sobre o Espaço Como Potencializador das Aprendizagens de Bebês e Crianças na Educação Infantil. In. MAGALHAES, C. EIDT, N. M. (Org.). Apropriações Teóricas e suas Implicações na Educação Infantil. 1ed.Curitiba: Editora CRV, 2019, v. 1, p. 1-247. https://doi.org/10.26512/2016.03.d.20028

LAZARETTI, L. M.; MELLO, M. A. . Como ensinar na educação infantil? Reflexões sobre a didática e o desenvolvimento da criança. In: PASQUALINI, J. C.; TEIXEIRA L. A.; AGUDO, M. M. (Org.). Pedagogia Histórico-Crítica: Legado e Perspectivas. 1ed.Uberlãndia: Navegando, 2018, v. 1.

LEONTIEV, A. Uma contribuição à teoria do desenvolvimento da psique infantil. In: VIGOTISKII, L S; LURIA, A; LEONTIEV, A. Linguagem, desenvolvimento e aprendizagem. São Paulo: Ícone editora, 2001.

MAGALHÃES, G.M. Atividade-guia e neoformações psíquicas: contribuições da Psicologia Histórico-Cultural para o ensino desenvolvente na Educação Infantil. Crítica Educativa (Sorocaba/SP), v. 4, n. 2, p. 275-286, jul./dez. 2018.

MARTINS, L. M. Especificidades do desenvolvimento afetivo-cognitivo de crianças de 4 a 6 anos. In. ARCE, A.; MARTINS, L. M. (Orgs.). Quem tem medo de ensinar na educação infantil? Em defesa do ato de ensinar. Campinas: Alínea, 2007. https://doi.org/10.1590/s1414-32832012000100025

MARTINS, L M. O desenvolvimento do psiquismo e a educação escolar: contribuições à luz da psicologia histórico-cultural e da pedagogia históricocrítica. Campinas, SP: Editora Autores Associados, 2013.

MARTINS, L. M.; MAGALHÃES, G. M. A educação infantil e suas interfaces formais e informais. In: BIZELLI, J. L.; SOUZA, C. B. G. (orgs) Caminhos para a escola inclusiva. São Paulo - SP: Cultura Acadêmica, 2014.

MÚJINA, V. S. Características Psicológicas del prepreescolar y del preescolar. In. PETROVSKI, A. V. (Org.). La psicología evolutiva y pedagógica. Moscú: Progreso, 1979. p. 44-79.

REIS, J.R.T. Família, emoção e ideologia. In: LANE, S. e CODO, W. (orgs) Psicologia Social: o homem em movimento. São Paulo: editora brasiliense, 2012. 
ROSEMBERG, F. O movimento de mulheres e a abertura política no Brasil: o caso da creche. Cadernos de Pesquisa, São Paulo. v. 51, p. 73-79, novembro 1984.

ROSEMBERG, F. Políticas Públicas e Qualidade da Educação Infantil. In: SANTOS, M. O.; RIBEIRO, M. I. S. (orgs.). Educação Infantil: os desafios estão postos!: e o que estamos fazendo? Salvador: Sooffset, 2014. https://doi.org/10.22533/at.ed.1241819125

SAVIANI, D. Pedagogia histórico-crítica: primeiras aproximações. Campinas: Autores Associados, 1991. https://doi.org/10.5212/praxeduc.v.8i1.0013

TUNES, E.; PRESTES, Z. Apontamentos sobre educação de bebês e de crianças pequenas. Rev. Teoria e Prática da Educação, v. 22, n.1, p. 32-43, Janeiro/Abril, 2019. https://doi.org/10.4025/tpe.v22i1.47427

VIEIRA, L. M. F. Mal Necessário: creches no departamento nacional da criança (1940-1970). Cadernos de Pesquisa, São Paulo. v. 67, p. 3-16, novembro de 1988.

VIGOTSKI, L.S. 7 aulas sobre os fundamentos da pedologia. Tradução e organização de Zoia Prestes e Elisabeth Tunes. Rio de Janeiro - RJ: E-papers, 2018.

VIGOTSKI, L S. A Construção do pensamento e da linguagem. São Paulo,SP: Martins Fontes, 2001.

VYGOTSKI, L S. Obras Escogidas. Madrid: Editora Visor, 1996. Tomo IV.

VIGOTSKII, L. S. Aprendizagem e desenvolvimento intelectual na idade escolar. In: VIGOTSKII, L. S.; LURIA, A. R.; LEONTIEV, A. N. Linguagem, desenvolvimento e aprendizagem. Tradução de Maria da Penha Villalobos. São Paulo: Ícone; EDUSP, 1988.

WEBER, L. N. D. (et all). Filhos em creches no século XXI e os sentimentos das mães. Psicologia Argumento, Curitiba, v. 24, n. 44 p. 45-54, jan./mar. 2006. https://doi.org/10.7213/rpa.v24i44.20095 